\title{
An Inventory-production Model for Supply Chain under Partial Backordering and Disruption
}

\author{
A. Taleizadeh ${ }^{1}$, H. Salehi ${ }^{2}$, L. A. San-José ${ }^{3, *}$ \\ We consider a three-level distribution network involving a raw material supplier with imperfect \\ quality, a manufacturer and several retailers. A production-inventory model accompanied by a \\ partial backlogging approach is developed by considering random disruptions. Any batch \\ received from the supplier is inspected by the manufacturer and if any flaw is visited, all the \\ goods in the inspected batch are rejected. The aim is to minimize the total cost. A heuristic \\ algorithm is presented to compute the optimal policy.
}

Keywords: Inventory management, EPQ, Partial backlogging, Disruption.

Manuscript was received on 31/03/2017 revised on 19/06/2017 and accepted for publication on 06/08/2017

\section{Introduction}

The classical economic order quantity (EOQ) pattern as the initial inventory problem was developed by Harris [5]. Taft [24] extended his work and studied the basic economic production quantity (EPQ) model. Many researchers considered EPQ models [4, 9, 17, 30]. Shortage is one of the assumptions in inventory problems, considered in the earlier works [32]. Different customer behaviors in a shortage situation led to other assumptions. Montgomery [11] considered one of those behaviors and extended the EOQ pattern through partial backordering (EOQ-PBO). The EOQ-PBO problem was studied by many investigators $[6,8,14,15,18,19,21,22,25,26,27$, 28, 31]. Mak [10] developed an EPQ-PBO model with time dependent-backorder cost and constant unit lost sale cost. Pentico and Drake [14] spread the Mak's program greatly and proposed a new method to optimize the objective function. San-José et al. [20] studied an EPQ-PBO model with a combination LIFO and FIFO between the dispatching policies. By relaxing perfect quality during the supply process, the inventory models with disruption (EOQD) were considered [1, 12, 23, 29]. Skouri et al. [23] considered the EOQD model with irregular defectives. Salehi et al. [16] extended the problem of Skouri et al. [23] by considering partial backordering situation (EOQD-PBO). Disruptions in supply chains may occur due to natural reasons, labor strikes, machine breakdowns, supplier stockouts or quality problems. Chiu et al. [2] considered disruptions due to machine breakdowns. They developed an EPQ model with disruption (EPQD) when some machinebreakdowns occurred according to a Poisson process. Chiu et al. [3] proposed an EPQD problem through unplanned machine failures and developed an optimal replenishment policy. Paul et al. [13] modeled an imperfect production inventory system and provided a genetic algorithm based on a search technique to solve the mathematical model. Some studies considered inventory in supply

\footnotetext{
${ }^{*}$ Corresponding Author.

${ }^{1}$ School of Industrial Engineering, College of Engineering, University of Tehran, Tehran, Iran, Email: taleizadeh@ut.ac.ir

${ }^{2}$ School of Industrial Engineering, South Tehran Branch, Islamic Azad University, Tehran, Iran, Email: st_h_salehi@azad.ac.ir

${ }^{3}$ IMUVA, Departamento de Matemática Aplicada, Universidad de Valladolid, Valladolid, Spain, E-mail: augusto@mat.uva.es
} 
chain decisions. Hu et al. [7] studied the ordering decisions in a situation of the PBO in a twoechelon supply chain.

Here, extending the work of Salehi et al. [16] an economic production quantity model with random disruption and partial backordering (EPQD-PBO) is developed. The cost function of the mathematical model includes holding, backlogging and lost sales. Applying this cost function, a novel solution method is proposed to optimize the objective function. The distinction between our work and that of Salehi et al. [16] is that we consider a finite production rate, and the economic production quantity situation under disruption and partial backordering is formulated, to develop the mathematical model. The reminder of our work is organized as follows. The EPQD-PBO model, and the problem statement are given in the next section. In Section 3, the optimization method is presented. The proposed algorithm for determining the optimum values, and numeric examples to verify the model applications are given in Section 4, and Section 5, respectively. Finally, a summary and some topics for further research are provided in Section 6.

\section{Model Description and Problem Statement}

Consider a three stages supply chain where the first level is the supplier with random imperfect quality who supplies raw materials in batches, the second level is the manufacturer who produces the final goods (with a constant production rate) to satisfy deterministic demands and some retailers on the demand side, and the third level involves some retailers (customers) with deterministic demands. The quality of the supplier is imperfect, and an "all or none" inspection policy is used by the inspection department of the manufacturer. In according to this policy, all the products of the inspected batches are rejected if any product with a low quality is visited. The construction ratio in the manufacturer is stable, and the exceeded retailer's demand is partially backordered. The structure of the chain is shown in Fig. 1.

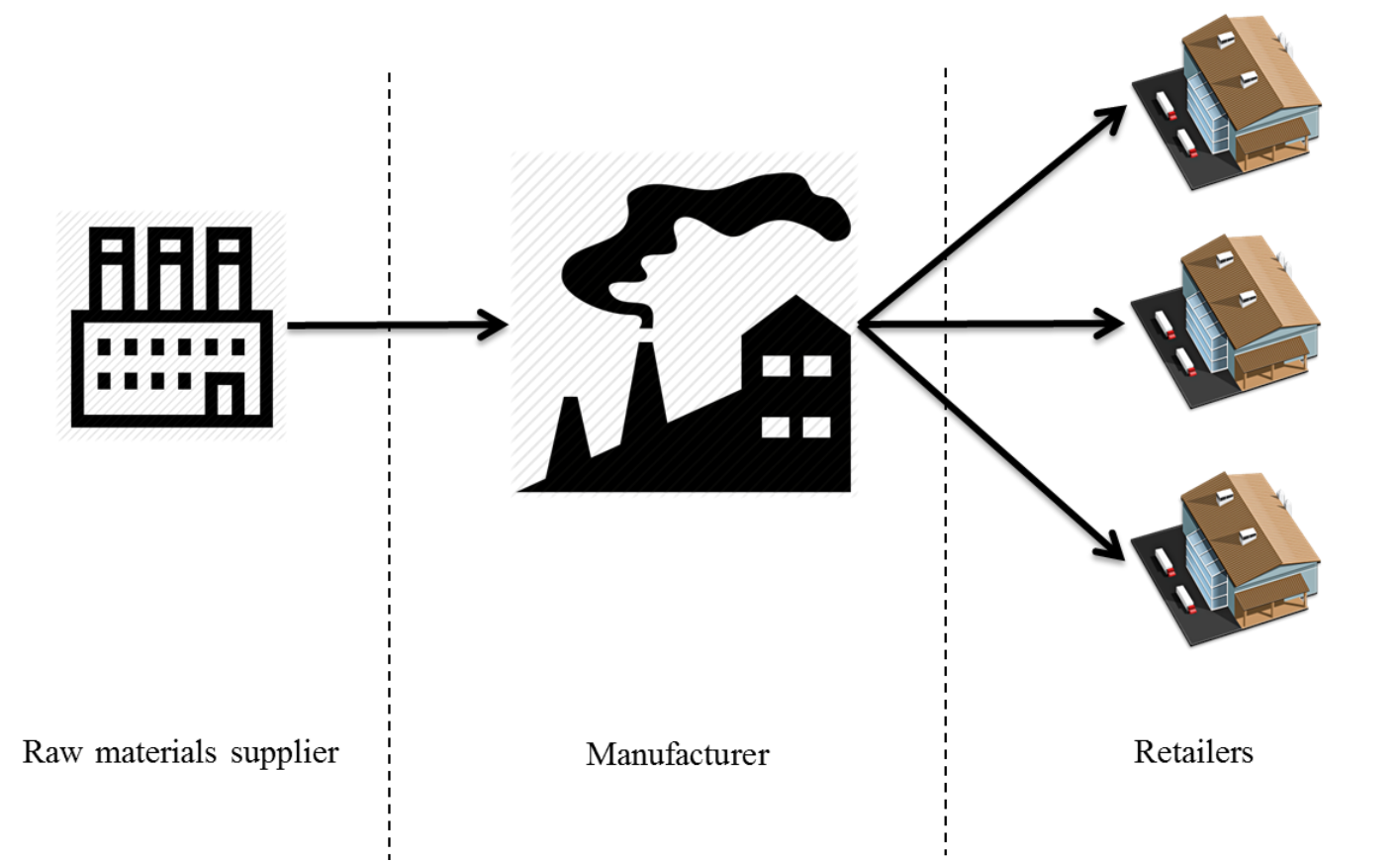

Figure 1. Schematic supply chain structure 
Our purpose here is a formulation of the manufacturer's mathematical model comprised of the total inventory cost. The essential notations and the primary assumptions used throughout our work are listed below.

\subsection{Notations}

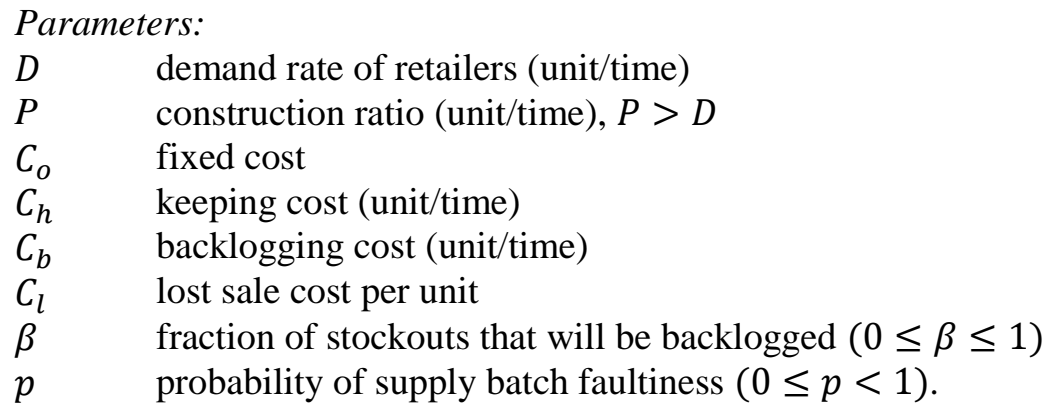

Variables:

$X \quad$ number of successive defective supply raw materials batches deliveries (a random variable)

$T$ time interval in between two succeeding supply transfers of the same type (that is, the two batches are both standard or both defective) (a decision variable)

$T^{\prime} \quad$ time interval in between two succeeding production intervals with positive inventory, that is, length of the inventory cycle (a random variable)

$F \quad$ A fraction of inventory cycle with positive inventory level (a decision variable)

Our assumptions are as follows:

(1) The demand is constant.

(2) The replenishment is continuous with a fixed rate.

(3) Shortages are permitted and partially backordered.

(4) The backorders are satisfied before the arriving orders (FIFO policy).

(5) There is a fixed time interval $T$ in the middle of two succeeding events.

(6) Imperfect deliveries happen with a definite probability, and they are independent of each other.

(7) An "all or none" inspection plan is considered.

\subsection{Calculating the Total Inventory cost}

For formulation of the mathematical cost function, understanding the system operation over time is essential. A typical cycle of the inventory model is shown in Fig. 2. Two general situations can occur within the inspection department: either the batches of raw material always have the required quality (in the case for perfect supply quality, $p=0$ ), or some batches with imperfect quality level $(p>0)$. In both cases, we consider that the fraction of backordered demand $(\beta)$ is a number in the interval $[0,1]$. Therefore, the two extreme cases corresponding to $X=0$, in which the whole demand through the stockout period is fallen (full lost sales), and corresponding to $X=1$, in which all demands are willing to wait for the next production run (complete backorders), are possible.

In the perfect quality situation $(p=0)$, all production-inventory cycles have the same length, $T^{\prime}=T$, and we are faced with a deterministic EPQ with partial backordering. However, in the 
second situation, the length of the production-inventory cycle is a random variable, whose probability distribution depends on the proportion that a supply batch is rejected $(p)$.

In the imperfect supply quality case, the defective raw material batches are rejected and the quantity of the next ordering (which would be received after $T$ ) should be enough to cover all the remaining demand. So, all backordered demand from time $T$ until time $(X+1) T$ should be supplied by producing during $\frac{\beta D X T}{P-\beta D}$ units of time (as shown in Fig. 2). In this way, we can define the duration of any inventory cycle $T^{\prime}$ relating to the accidental variable $X$ as: $T^{\prime}=(X+1) T+\frac{\beta D X T}{P-\beta D}$. Additionally, $X$ is a geometric random variable with parameter $p$ (see Salehi et al. [16]) and probability mass function $\operatorname{Pr}(X=x)=p^{x}(1-p), x \geq 0$.

A typical cycle $\left(T^{\prime}=2 T+\frac{\beta D T}{P-\beta D}\right)$ is illustrated in Fig. 2, where a faulty raw material delivery at time $T$ is refused. As shown in the figure, a regular production and inventory interval (the first-time interval of length $T$ in the inventory cycle) can be split into four time-intervals (Pentico et al. [15]). The terms of $I$ and $B$ respectively represent the maximum of inventory level and the backorder level. According to Fig. 2, we have: $I=\left(P_{r}-D\right) t_{1}=D t_{2}$ and $B=\beta D t_{3}=\left(P_{r}-\beta D\right) t_{4}$. In duration of $t_{1}+t_{2}$, all the demand is supported from the stock, and we have $t_{1}+t_{2}=F T$. On the other hand, intervals $t_{3}$ and $t_{4}$ complement intervals $t_{1}$ and $t_{2}$, and so $t_{3}+t_{4}=(1-F) T$. By considering these relations and after doing some algebra, the lengths of these intervals are obtained to be

$$
\begin{aligned}
& t_{1}=F T\left(\frac{D}{P}\right), \\
& t_{2}=F T\left(1-\frac{D}{P}\right), \\
& t_{3}=(1-F) T\left(1-\frac{\beta D}{P}\right), \\
& t_{4}=(1-F) T\left(\frac{\beta D}{P}\right) .
\end{aligned}
$$

We formulated the model in relation to two decision variables $(F, T)$. So, the inventory-related costs of the manufacturer, $C C(F, T, X)$, in a cycle of length $T^{\prime}$ is calculated as follows:

$$
\begin{aligned}
C C(F, T, X) & =(X+1) C_{o}+\frac{C_{h} D T^{2} F^{2}}{2}\left(1-\frac{D}{P}\right)+\frac{\beta C_{b} D T^{2}(1-F)^{2}}{2}\left(1-\frac{\beta D}{P}\right) \\
& +\frac{\beta C_{b} D T^{2} X^{2}}{2}\left(1+\frac{\beta D}{P-\beta D}\right)+C_{l} D T(1-\beta)(X+1-F) \\
& +C_{l} D T(1-\beta)\left(\frac{\beta D X}{P-\beta D}\right) .
\end{aligned}
$$

Since the expected value and the second moment of $X$ can be calculated via $E(X)=\frac{p}{1-p}$ and $E\left(X^{2}\right)=\operatorname{Var}(X)+(E(X))^{2}=\frac{p}{(1-p)^{2}}+\frac{p^{2}}{(1-p)^{2}}=\frac{p(1+p)}{(1-p)^{2}}$, the expected value of $C C(F, T, X)$ is as follows: 


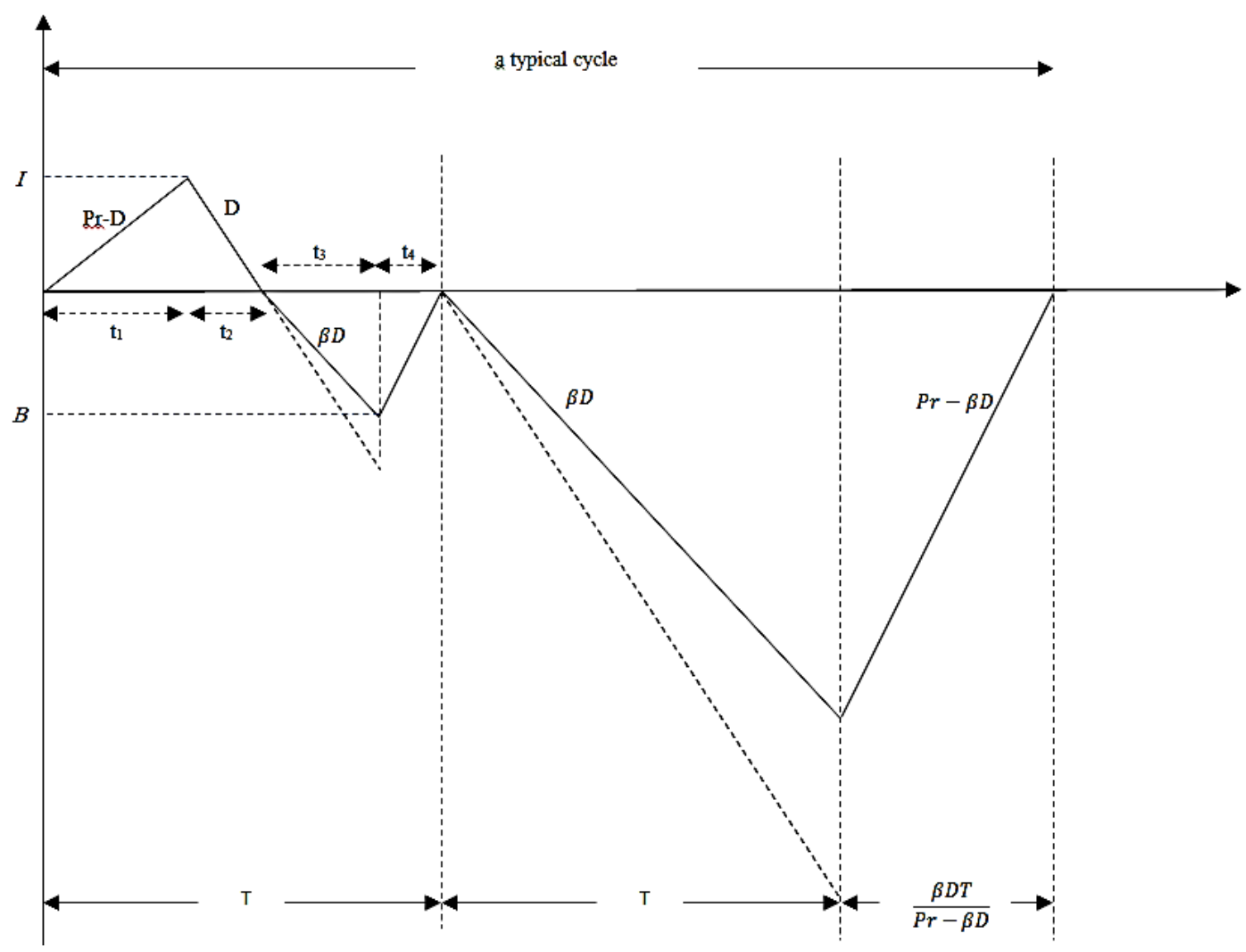

Figure 2. A typical cycle of length $T^{\prime}$ in EPQD-PBO

$$
\begin{aligned}
& C(F, T)=\frac{C_{o}}{1-p}+\frac{C_{h} D T^{2} F^{2}}{2}\left(1-\frac{D}{P}\right)+\frac{\beta C_{b} D T^{2}(1-F)^{2}}{2}\left(1-\frac{\beta D}{P}\right) \\
& +\frac{\beta C_{b} D T^{2}\left(1+\frac{\beta D}{P-\beta D}\right)}{2} * \frac{p(1+p)}{(1-p)^{2}} \\
& +C_{l} D T(1-\beta)\left(\frac{1}{1-p}-F+\frac{\beta D p}{(1-p)(P-\beta D)}\right) .
\end{aligned}
$$

Since $T^{\prime}=(X+1) T+\frac{\beta D X T}{P-\beta D}$, we have

$$
E\left(T^{\prime}\right)=T\left(E(X)+1+\frac{\beta D * E(X)}{P-\beta D}\right)=T\left(\frac{P-\beta D+\beta D p}{(1-p)(P-\beta D)}\right)
$$


To simplify the notation, we define $\alpha=\left(\frac{P-\beta D+\beta D p}{(1-p)(P-\beta D)}\right)$, and consequently the expected value of every inventory cycle is simplified to be

$$
E\left(T^{\prime}\right)=\alpha T
$$

and the expected cost per unit time is

$$
\begin{aligned}
& T C(F, T)=\frac{C(F, T)}{E\left(T^{\prime}\right)} \\
& =\frac{C_{o}}{\alpha T(1-p)}+\frac{C_{h} D T F^{2}}{2 \alpha}\left(1-\frac{D}{P}\right)+\frac{\beta C_{b} D T(1-F)^{2}}{2 \alpha}\left(1-\frac{\beta D}{P}\right) \\
& +\frac{\beta C_{b} D T\left(1+\frac{\beta D}{P-\beta D}\right)}{2 \alpha} * \frac{p(1+p)}{(1-p)^{2}}+\frac{C_{l} D(1-\beta)(\alpha-F)}{\alpha} .
\end{aligned}
$$

\section{Model Optimization}

To solve the objective function of the manufacturer, Minimize $T C(F, T)$, subject to $T>0$ and $0 \leq F \leq 1$ we can simplify the notation and rewrite (5) as follows:

$$
T C(F, T)=\frac{C_{o}^{\prime}}{T}+C_{h}^{\prime} D T F^{2}+\beta C_{b}^{\prime} D T(1-F)^{2}+\beta C_{b}^{\prime \prime} D T+C_{l}^{\prime} D(\alpha-F),
$$

where:

$$
C_{o}^{\prime}=\frac{C_{o}}{\alpha(1-p)}, C_{h}^{\prime}=\frac{C_{h}}{2 \alpha}\left(1-\frac{D}{P}\right), C_{b}^{\prime}=\frac{C_{b}}{2 \alpha}\left(1-\frac{\beta D}{P}\right), C_{b}^{\prime \prime}=\frac{C_{b}\left(1+\frac{\beta D}{P-\beta D}\right)}{2 \alpha} \times \frac{p(1+p)}{(1-p)^{2}}, C_{l}^{\prime}=\frac{C_{l}(1-\beta)}{\alpha} .
$$

For a fixed value of $T$, Eq. (6) is a quadratic function that obtains its minimal value at

$$
F^{*}(T)=\left\{\begin{array}{cc}
\frac{C_{l}^{\prime}+2 \beta C_{b}^{\prime} T}{2 T\left(C_{h}^{\prime}+\beta C_{b}^{\prime}\right)}, & \text { if } T \geq C_{l}^{\prime} / 2 C_{h}^{\prime} \\
1, & \text { if } T<C_{l}^{\prime} / 2 C_{h}^{\prime}
\end{array}\right.
$$

with the optimal value of

$$
T C\left(F^{*}(T), T\right)= \begin{cases}W_{1}(T)=\frac{C_{o}^{\prime}}{T}+\left(C_{h}^{\prime}+\beta C_{b}^{\prime \prime}\right) D T+C_{l}^{\prime} D(\alpha-1), & \text { if } T<C_{l}^{\prime} / 2 C_{h}^{\prime} \\ W_{2}(T)=\frac{a_{o}}{T}+a_{1} T+a_{2}, & \text { if } T \geq C_{l}^{\prime} / 2 C_{h}^{\prime}\end{cases}
$$

where 


$$
a_{o}=\frac{4 C_{o}^{\prime}\left(C_{h}^{\prime}+\beta C_{b}^{\prime}\right)-C_{l}^{\prime 2} D}{4\left(C_{h}^{\prime}+\beta C_{b}^{\prime}\right)}, a_{1}=\frac{\beta D\left[C_{h}^{\prime}\left(C_{b}^{\prime}+C_{b}^{\prime \prime}\right)+\beta C_{b}^{\prime} C_{b}^{\prime \prime}\right]}{C_{h}^{\prime}+\beta C_{b}^{\prime}} \geq 0, a_{2}=\frac{C_{l}^{\prime} D\left(\alpha C_{h}^{\prime}+(\alpha-1) \beta C_{b}^{\prime}\right)}{C_{h}^{\prime}+\beta C_{b}^{\prime}} \geq 0
$$

Next, we determine the optimal value $T^{*}$ such that $\operatorname{TC}\left(F^{*}(T), T\right)$ is minimized. Notice that $T C\left(F^{*}(T), T\right)$ is a continuous function over all $T>0$. The first derivative of $T C\left(F^{*}(T), T\right)$ is

$$
\frac{d}{d T} T C\left(F^{*}(T), T\right)= \begin{cases}W_{1}^{\prime}(T)=\frac{-C_{o}^{\prime}}{T^{2}}+\left(C_{h}^{\prime}+\beta C_{b}^{\prime \prime}\right) D, & \text { if } T<C_{l}^{\prime} / 2 C_{h}^{\prime} \\ W_{2}^{\prime}(T)=\frac{-a_{o}}{T^{2}}+a_{1}, & \text { if } T>C_{l}^{\prime} / 2 C_{h}^{\prime} .\end{cases}
$$

Since $W_{1}^{\prime}\left(C_{l}^{\prime} / 2 C_{h}^{\prime}\right)=W_{2}^{\prime}\left(C_{l}^{\prime} / 2 C_{h}^{\prime}\right)$, the above derivative is a continuous function over $T>0$. We have the following cases:

1. If $a_{o}<0$, then $W_{2}(T)$ is a strictly growing function for $T>C_{l}^{\prime} / 2 C_{h}^{\prime}, W_{1}(T)$ is a strictly reducing function for $T \in\left(0, T_{o}\right)$, in addition to being a strictly increasing function for $T \in\left(T_{o}, C_{l}^{\prime} / 2 C_{h}^{\prime}\right)$, where

$$
T_{o}=\sqrt{\frac{C_{o}^{\prime}}{D\left(C_{h}^{\prime}+\beta C_{b}^{\prime \prime}\right)}} .
$$

Therefore, $\operatorname{TC}\left(F^{*}(T), T\right)$ obtains its minimal value at $T_{o}$.

2. If $a_{o}=0$, then two situations can occur:

(i) If $\beta=0$, then $W_{2}(T)$ is a constant function and $W_{1}(T)$ is a strictly decreasing function for $T \in\left(0, C_{l}^{\prime} / 2 C_{h}^{\prime}\right)$. In consequence, $\operatorname{TC}\left(F^{*}(T), T\right)$ obtains its minimal value at any point of the interval $\left[C_{l}^{\prime} / 2 C_{h}^{\prime}, \infty\right)$.

(ii) If $\beta>0$, then it is immediate that $T C\left(F^{*}(T), T\right)$ obtains its minimal value at $T_{o}$.

3. If $a_{o}>0$, then we consider the following situations:

(i) If $\beta=0$, then $W_{1}(T)$ is a strictly decreasing function for $T \in\left(0, C_{l}^{\prime} / 2 C_{h}^{\prime}\right)$ and $W_{2}(T)$ is also strictly decreasing in its domain. In consequence, $T C\left(F^{*}(T), T\right)$ attains its minimum value at $\infty$.

(ii) If $\beta>0$, then: (a) $T C\left(F^{*}(T), T\right)$ obtains its minimal value at $T_{o}$, when $T_{o} \leq C_{l}^{\prime} / 2 C_{h}^{\prime}$ or otherwise, (b) $T C\left(F^{*}(T), T\right)$ obtains its minimal value at $T_{1}$, where

$$
T_{1}=\sqrt{\frac{a_{o}}{a_{1}}} .
$$

\section{Algorithm for Determining the Optimal Value}

Taking into account the presented results, we propose the following algorithm to solve the model. 


\section{Algorithm 1. Method for solving the model.}

Step 1: Calculate $a_{o}=\frac{4 C_{o}^{\prime}\left(C_{h}^{\prime}+\beta C_{b}^{\prime}\right)-C_{l}^{\prime 2} D}{4\left(C_{h}^{\prime}+\beta C_{b}^{\prime}\right)}$.

Step 2: If $a_{o}<0$ then

$$
T^{*}=T_{o}=\sqrt{\frac{C_{o}^{\prime}}{D\left(C_{h}^{\prime}+\beta C_{b}^{\prime \prime}\right)}}, F^{*}=1, T C^{*}=2 \sqrt{C_{o}^{\prime} D\left(C_{h}^{\prime}+\beta C_{b}^{\prime \prime}\right)}+C_{l}^{\prime} D(\alpha-1) .
$$

Step 3: If $a_{o}=0$ then

$$
\text { begin }
$$

$$
\text { If } \beta=0 \text { then }
$$

$$
T^{*} \in\left[C_{l}^{\prime} / 2 C_{h}^{\prime}, \infty\right), F^{*}=C_{l}^{\prime} / 2 T^{*} C_{h}^{\prime}, T C^{*}=\alpha C_{l}^{\prime} D
$$

else if $\beta>0$ then

end

$$
T^{*}=T_{o}=\sqrt{\frac{C_{o}^{\prime}}{D\left(C_{h}^{\prime}+\beta C_{b}^{\prime \prime}\right)}}, F^{*}=1, T C^{*}=2 \sqrt{C_{o}^{\prime} D\left(C_{h}^{\prime}+\beta C_{b}^{\prime \prime}\right)}+C_{l}^{\prime} D(\alpha-1)
$$

Step 4: If $a_{o}>0$ then begin

$$
\begin{aligned}
& \text { If } \beta=0 \text { then } \\
& \qquad T^{*}=\infty, F^{*}=0, T C^{*}=\alpha C_{l}^{\prime} D=C_{l} D
\end{aligned}
$$

else if $\beta>0$ then

$$
\begin{aligned}
& \text { If } T_{o}=\sqrt{\frac{C_{o}^{\prime}}{D\left(C_{h}^{\prime}+\beta C_{b}^{\prime \prime}\right)}} \leq C_{l}^{\prime} / 2 C_{h}^{\prime} \text { then } \\
& \qquad T^{*}=T_{o}, F^{*}=1, T C^{*}=2 \sqrt{C_{o}^{\prime} D\left(C_{h}^{\prime}+\beta C_{b}^{\prime \prime}\right)}+C_{l}^{\prime} D(\alpha-1) \\
& \text { else if } T_{o}=\sqrt{\frac{C_{o}^{\prime}}{D\left(C_{h}^{\prime}+\beta C_{b}^{\prime \prime}\right)}}>C_{l}^{\prime} / 2 C_{h}^{\prime} \text { then } \\
& \text { begin } \\
& \text { Calculate } a_{1}=\frac{\beta D\left[C_{h}^{\prime}\left(C_{b}^{\prime}+C_{b}^{\prime \prime}\right)+\beta C_{b}^{\prime} C_{b}^{\prime \prime}\right]}{C_{h}^{\prime}+\beta C_{b}^{\prime}}, \\
& \qquad T^{*}=T_{1}=\sqrt{\frac{a_{o}}{a_{1}}}, F^{*}=\left(C_{l}^{\prime}+2 \beta C_{b}^{\prime} T^{*}\right) / 2 T^{*}\left(C_{h}^{\prime}+\beta C_{b}^{\prime}\right), \\
& \text { end } T C^{*}=2 \sqrt{a_{o} a_{1}}+\left(\left[C_{l}^{\prime} D\left(\alpha C_{h}^{\prime}+(\alpha-1) \beta C_{b}^{\prime}\right)\right] /\left(C_{h}^{\prime}+\beta C_{b}^{\prime}\right)\right) .
\end{aligned}
$$

end

Step 5: Stop.

\section{Numerical Experiments}

Here, several numerical examples are worked through.

Example 1: Consider an inventory-production problem that satisfies the assumptions given in Section 2 with $D=1100$ (units/year), $C_{o}=275$ (\$/order), $C_{b}=3.2$ (\$/unit/year), $C_{h}=2$ (\$/unit/year), $C_{l}=4$ (\$/unit lost), $P_{r}=9200$ (units/year), $p=0.10, \beta=0.20$. Applying Algorithm 1 , we have

Step 1: Calculate $a_{o}$

$$
a_{o}=\frac{4 C_{o}^{\prime}\left(C_{h}^{\prime}+\beta C_{b}^{\prime}\right)-C_{l}^{\prime 2} D}{4\left(C_{h}^{\prime}+\beta C_{b}^{\prime}\right)}=\frac{4(274.33)(0.79+(0.2)(1.40))-\left((2.87)^{2}(1100)\right)}{4(0.79+(0.2)(1.40))}=-1845.26 .
$$

Step 2: Since $a_{o}<0$, we compute 


$$
\begin{aligned}
T^{*} & =T_{o}=\sqrt{\frac{C_{o}^{\prime}}{D\left(C_{h}^{\prime}+\beta C_{b}^{\prime \prime}\right)}}=\sqrt{\frac{274.33}{1100(0.79+(0.20)(0.20))}}=0.548010, \\
F^{*} & =1 \\
T C^{*} & =2 \sqrt{C_{o}^{\prime} D\left(C_{h}^{\prime}+\beta C_{b}^{\prime \prime}\right)}+C_{l}^{\prime} D(\alpha-1) \\
& =2 \sqrt{(274.33)(1100)(0.79+(0.20)(0.20))}+(2.87)(1100)(1.11-1)=1360.92 .
\end{aligned}
$$

Example 2: Use the input data given in Example 1, except that the value of $\beta$ is changed to $\beta=$ 0.8. Applying Algorithm 1, we obtain:

Step 1: Calculate $a_{o}$ :

$$
a_{o}=\frac{4 C_{o}^{\prime}\left(C_{h}^{\prime}+\beta C_{b}^{\prime}\right)-C_{l}^{\prime 2} D}{4\left(C_{h}^{\prime}+\beta C_{b}^{\prime}\right)}=\frac{4(272.12)(0.78+(0.8)(1.29))-\left((0.71)^{2}(1100)\right)}{4(0.78+(0.8)(1.29))}=195.212 .
$$

Since $a_{o}>0$, step 4 is executed.

Step 4: $\beta>0$, and thus $T_{0}$ is computed and compared to $\left(C_{l}^{\prime} / 2 C_{h}^{\prime}=0.71 /(2)(0.78)=\right.$ 0.454321):

$$
T_{o}=\sqrt{\frac{C_{o}^{\prime}}{D\left(C_{h}^{\prime}+\beta C_{b}^{\prime \prime}\right)}}=\sqrt{\frac{272.12}{1100(0.78+(0.80)(0.21))}}=0.508886
$$

Since $T_{o}>C_{l}^{\prime} / 2 C_{h}^{\prime}$, then we

Calculate $a_{1}=\frac{\beta D\left[C_{h}^{\prime}\left(C_{b}^{\prime}+C_{b}^{\prime \prime}\right)+\beta C_{b}^{\prime} C_{b}^{\prime \prime}\right]}{C_{h}^{\prime}+\beta C_{b}^{\prime}}=\frac{(0.8)(1100)[(0.78)(1.29+0.21)+((0.8)(1.29)(0.21))]}{(0.78)+(0.8)(1.29)}$

$$
\begin{aligned}
& a_{1}=678.195 \\
& T^{*}=T_{1}=\sqrt{\frac{a_{o}}{a_{1}}}=\sqrt{\frac{195.21}{678.20}}=0.536508 \\
& F^{*}=\left(C_{l}^{\prime}+2 \beta C_{b}^{\prime} T^{*}\right) / 2 T^{*}\left(C_{h}^{\prime}+\beta C_{b}^{\prime}\right) \\
& =(0.71+(2)(0.8)(1.29)(0.54)) /(2)(0.54)(0.78+(0.80)(1.29))=0.933821, \\
& T C^{*}=2 \sqrt{a_{o} a_{1}}+\left(\left[C_{l}^{\prime} D\left(\alpha C_{h}^{\prime}+(\alpha-1) \beta C_{b}^{\prime}\right)\right] /\left(C_{h}^{\prime}+\beta C_{b}^{\prime}\right)\right) \\
& =(2) \sqrt{(195.21)(678.20)} . \\
& +([(0.71)(1100)((1.12)(0.78)+(1.12-1)(0.8)(1.29))] /((0.78)+(0.8)(1.29)))
\end{aligned}
$$




$$
=1162.57 \text {. }
$$

Example 3: Use the same input data given in Example 2, except that the value of $p$ is changed to $p=0.5$. Following the algorithm, we get

Step 1: Calculate $a_{o}$ :

$$
a_{o}=\frac{4 C_{o}^{\prime}\left(C_{h}^{\prime}+\beta C_{b}^{\prime}\right)-C_{l}^{\prime 2} D}{4\left(C_{h}^{\prime}+\beta C_{b}^{\prime}\right)}=\frac{4(261.19)(0.42+(0.8)(0.69))-\left((0.38)^{2}(1100)\right)}{4(0.42+(0.8)(0.69))}=220.176
$$

Since $a_{o}>0$, then step 4 is executed.

Step 4: Since $\beta>0$, then $T_{0}$ is computed and compared to $\left(\mathrm{C}_{\mathrm{l}}^{\prime} / 2 \mathrm{C}_{\mathrm{h}}^{\prime}=0.38 /(2)(0.42)=\right.$ $0.454321)$ :

$$
T_{o}=\sqrt{\frac{C_{o}^{\prime}}{D\left(C_{h}^{\prime}+\beta C_{b}^{\prime \prime}\right)}}=\sqrt{\frac{261.19}{1100(0.42+(0.80)(2.52))}}=0.312299
$$

Since $T_{o}<C_{l}^{\prime} / 2 C_{h}^{\prime}$, then

$T^{*}=T_{o}=0.312299$,

$F^{*}=1$,

$T C^{*}=2 \sqrt{C_{o}^{\prime} D\left(C_{h}^{\prime}+\beta C_{b}^{\prime \prime}\right)}+C_{l}^{\prime} D(\alpha-1)$

$=2 \sqrt{(261.19)(1100)((0.42)+(0.8)(2.52))}+(0.38)(1100)(2.11-1)$

$=2134.77$.

\section{Conclusions}

We extended an inventory-production problem in a three-level supply chain with random disruption in the delivery of raw material batches at the supply side of the network (under an "all or none" inspection policy, defective raw materials, due to quality problems, were rejected). The exceeded retailers' demand was partially backordered by the manufacturer as the focal level. After modeling the EPQD-PBO problem, a solution method was proposed to optimize the extended cost function. Numerical examples were worked through to illustrate the steps of the proposed algorithm. Future research may consider stochastic demands. Furthermore, it is possible to extend the model for expanded supply chains with various facilities. 


\section{Acknowledgements}

The first author would like to thank the financial support of University of Tehran for this research under grant number 30015-1-04. This work is partially supported by the Spanish Ministry of Science and Innovation (MCI) and European FEDER funds through the research project MTM201343396-P for the third author.

\section{References}

[1] Chang, H.C., and Ho, C.H. (2010), Exact closed-form solutions for "optimal inventory model for items with imperfect quality and shortage backordering", Omega, 38(3), 233-237.

[2] Chiu, S.W., Wang, S.L., and Chiu, Y.S.P. (2007), Determining the optimal run time for EPQ model with scrap, rework, and stochastic breakdowns, European Journal of Operational Research, 180(2), 664-676.

[3] Chiu, S.W., Chou, C.L., and Wu, W.K. (2013), Optimizing replenishment policy in an EPQbased inventory model with nonconforming items and breakdown, Economic Modelling, 35, 330-337.

[4] Chiu, Y.S.P., and Ting, C.K. (2010), A note on "Determining the optimal run time for EPQ model with scrap, rework, and stochastic breakdowns", European Journal of Operational Research, 201(2), 641-643.

[5] Harris, F.W. (1913), How many parts to make at once. Factory, the magazine of management, 10(2), 135-136.

[6] Hsieh, T.P., and Dye, C.Y. (2012), A note on "The EPQ with partial backordering and phasedependent backordering rate", Omega, 40(1), 131-133.

[7] Hu, F., Lim, C.C., and Lu, Z. (2014), Optimal production and procurement decisions in a supply chain with an option contract and partial backordering under uncertainties, Applied Mathematics and Computation, 232, 1225-1234.

[8] Karimi-Nasab, M., and Wee, H.M. (2015), An inventory model with truncated exponential replenishment intervals and special sale offer, Journal of Manufacturing Systems, 35, 246250.

[9] Li, J., Wang, S., and Cheng, T.E. (2008), Analysis of postponement strategy by EPQ-based models with planned backorders, Omega, 36(5), 777-788.

[10] Mak, K.L. (1987), Determining optimal production-inventory control policies for an inventory system with partial backlogging, Computers and Operations Research, 14(4), 299304.

[11] Montgomery, D.C., Bazaraa, M.S., and Keswani, A.K. (1973), Inventory models with a mixture of backorders and lost sales, Naval Research Logistics Quarterly, 20(2), 255-263.

[12] Parlar, M., and Berkin, D. (1991), Future supply uncertainty in EOQ models, Naval Research Logistics, 38(1), 107-121.

[13] Paul, S.K., Sarker, R., and Essam, D. (2015), Managing disruption in an imperfect production-inventory system, Computers and Industrial Engineering, 84, 101-112.

[14] Pentico, D.W., and Drake, M.J. (2009), The deterministic EOQ with partial backordering: a new approach, European Journal of Operational Research, 194(1), 102-113.

[15] Pentico, D.W., Drake, M.J., and Toews, C. (2011), The EPQ with partial backordering and phase-dependent backordering rate, Omega, 39(5), 574-577.

[16] Salehi, H., Taleizadeh, A.A., and Tavakkoli-Moghaddam, R. (2016), An EOQ model with random disruption and partial backordering. International Journal of Production Research, 54(9), 2600-2609. 
[17] Sana, S.S. (2010), An economic production lot size model in an imperfect production system, European Journal of Operational Research, 201(1), 158-170.

[18] San-José, L.A., García-Laguna, J., and Sicilia, J. (2009a), An economic order quantity model with partial backlogging under general backorder cost function, Top, 17(2), 366-384.

[19] San-José, L.A., Sicilia, J., and García-Laguna, J. (2009b), A general model for EOQ inventory systems with partial backlogging and linear shortage costs, International Journal of Systems Science, 40(1), 59-71.

[20] San-José, L.A., Sicilia, J., and García-Laguna, J. (2014), Optimal lot size for a productioninventory system with partial backlogging and mixture of dispatching policies, International Journal of Production Economics, 155, 194-203.

[21] San-José, L.A., Sicilia, J., and García-Laguna, J. (2015), Analysis of an EOQ inventory model with partial backordering and non-linear unit holding cost, Omega, 54, 147-157.

[22] Sicilia, J., San-José, L.A., and García-Laguna, J. (2012), An inventory model where backordered demand ratio is exponentially decreasing with the waiting time, Annals of Operations Research, 1-19.

[23] Skouri, K., Konstantaras, I., Lagodimos, A.G., and Papachristos, S. (2014), An EOQ model with backorders and rejection of defective supply batches, International Journal of Production Economics, 155, 148-154.

[24] Taft, E.W. (1918), The most economical production lot, Iron Age, 101(18), 1410-1412.

[25] Taleizadeh, A.A., Pentico, D.W., Aryanezhad, M., and Ghoreyshi, S.M. (2012), An economic order quantity model with partial backordering and a special sale price, European Journal of Operational Research, 221(3), 571-583.

[26] Taleizadeh, A.A., Pentico, D.W., Jabalameli, M.S., and Aryanezhad, M. (2013a), An EOQ model with partial delayed payment and partial backordering, Omega, 41(2), 354-368.

[27] Taleizadeh, A.A., Pentico, D.W., Jabalameli, M.S., and Aryanezhad, M. (2013b), An economic order quantity model with multiple partial prepayments and partial backordering, Mathematical and Computer Modelling, 57(3), 311-323.

[28] Taleizadeh, A.A., and Pentico, D.W. (2013), An economic order quantity model with a known price increase and partial backordering, European Journal of Operational Research, 228(3), 516-525.

[29] Wee, H.M., Yu, J., and Chen, M.C. (2007), Optimal inventory model for items with imperfect quality and shortage backordering, Omega, 35(1), 7-11.

[30] Zhang, R.Q. (2009), A note on the deterministic EPQ with partial backordering, Omega, 37(5), 1036-1038.

[31] Zhang, R.Q., Kaku, I., and Xiao, Y.Y. (2011), Deterministic EOQ with partial backordering and correlated demand caused by cross-selling, European Journal of Operational Research, 210(3), 537-551.

[32] Zipkin, P.H. (2000), Foundations of inventory management (Vol. 2). New York: McGrawHill. 